\title{
Neuroprotective Effects of the Nonpsychoactive Cannabinoid Cannabidiol in Hypoxic-Ischemic Newborn Piglets
}

\author{
FRANCISCO J. ALVAREZ, HECTOR LAFUENTE, M. CARMEN REY-SANTANO, VICTORIA E. MIELGO, ELENA GASTIASORO,
} MIGUEL RUEDA, ROGER G. PERTWEE, ANA I. CASTILLO, JULIÁN ROMERO, AND JOSÉ MARTÍNEZ-ORGADO

\author{
Laboratorio de Fisiopatología Perinatal Experimental [F.J.A., H.L., M.C.R.-S., V.E.M., E.G.], Department of Biochemistry [M.R.], \\ Gurutzetako Ospitalea, Bilbo, Bizkaia, Spain; School of Medical Sciences [R.G.P.], University of Aberdeen, AB25 2ZD Scotland; \\ Laboratorio de Apoyo a la Investigación [A.I.C., J.R., J.M.-O.], Fundación Hospital Alcorcón, and Centro de Investigación Biomédica en \\ Red sobre Enfermedades Neurodegenerativas (CIBERNED) CB06/05/1109, Madrid, 28922 Spain
}

\begin{abstract}
To test the neuroprotective effects of the nonpsychoactive cannabinoid cannabidiol (CBD), piglets received i.v. CBD or vehicle after hypoxia-ischemia (HI: temporary occlusion of both carotid arteries plus hypoxia). Nonhypoxic-ischemic sham-operated piglets remained as controls. Brain damage was studied by near-infrared spectroscopy (NIRS) and amplitudeintegrated electroencephalography (aEEG) and by histologic assessment (Nissl and FluoroJadeB staining). In HI+vehicle, HI led to severe cerebral hemodynamic and metabolic impairment, as reflected in NIRS by an increase in total $\mathrm{Hb}$ index (THI) and a decrease in the fractional tissue oxygenation extraction (FTOE); in $\mathrm{HI}+\mathrm{CBD}$ the increase of THI was blunted and FTOE remained similar to SHAM. HI profoundly decreased EEG amplitude, which was not recovered in $\mathrm{HI}+$ vehicle, indicating cerebral hypofunction; seizures were observed in all $\mathrm{HI}+$ vehicle. In $\mathrm{HI}+\mathrm{CBD}$, however, EEG amplitude recovered to $46.4 \pm 7.8 \%$ baseline and seizures appeared only in $4 / 8$ piglets (both $p<0.05$ ). The number of viable neurons decreased and that of degenerating neurons increased in $\mathrm{HI}+$ vehicle; CBD reduced both effects by more than $50 \%$. CBD administration was free from side effects; moreover, CBD administration was associated with cardiac, hemodynamic, and ventilatory beneficial effects. In conclusion, administration of CBD after HI reduced short-term brain damage and was associated with extracerebral benefits. (Pediatr Res 64: 653-658, 2008)
\end{abstract}

$\mathrm{S}^{\mathrm{c}}$ everal studies have pointed to cannabinoids as substances with a high potential as neuroprotective treatments in ischemic or traumatic brain damage $(1,2)$. Lately, our group has demonstrated that the cannabinoid receptor agonist WIN55212-2 induces signs of neuroprotection in both in vitro and in vivo models of neonatal hypoxic-ischemic encephalopathy (NHIE) in rats $(3,4)$. Because the production of psychoactive effects is likely to limit the therapeutic value of compounds such as WIN55212-2, we have now also performed experiments with cannabidiol (CBD), a major nonpsychoactive constituent of cannabis. Importantly, CBD has been found to induce neuroprotective effects in both in vitro and in vivo studies (5-9). These neuroprotective effects are thought to rely mainly on the potent antiinflammatory and antioxidant prop-

Received May 7, 2008; accepted July 7, 2008.

Correspondence: José Martínez-Orgado, M.D., Ph.D., Laboratorio de Apoyo a la Investigación, Fundación Hospital Alcorcón, Budapest, 1. 28922-Alcorcón, Madrid, Spain; e-mail: josemorg@telefonica.net

Supported by grants from FIS-PI060839 (F.J.A.), FIS-PI061085 (J.M.-O.), S-SAL/ 0261/2006 and SAF 2007-61565 (J.R.). erties of CBD $(6,9,10)$, although inhibition of calcium transport across membranes, inhibition of anandamide uptake and enzymatic hydrolysis, and inhibition of iNOS protein expression and NF- $\kappa \mathrm{B}$ activation $(6,9,11)$ might also account for CBD-induced neuroprotection.

The aim of the present work was to study the neuroprotective effect of CBD by using the temporary occlusion of both carotid arteries combined with hypoxia animal model, considered as very close to actual perinatal asphyxia in human neonates (12). In addition, we aimed to test the protective effect of CBD by using the two best devices available for actual bedside studies in asphyxiated newborns: near-infrared spectroscopy (NIRS), a noninvasive optical technique for assessing circulation and oxygenation in brain, and amplitudeintegrated electroencephalography (aEEG). Neuroprotection by CBD was also assessed by histologic study. Finally, we also aimed to test whether CBD administration was free of significant clinical side effects.

\section{METHODS}

\begin{abstract}
Animal preparation. The experimental protocol met European and Spanish regulations for animal research (EU 86/609 and RD 1201/2005). Piglets 3 to 5-d old were anesthetized with a perfusion of phentanil, propofol, and midazolam in dextrose $5 \%(0.004,3$, and $0.5 \mathrm{mg} / \mathrm{kg} / \mathrm{h}$, respectively) and paralyzed by a perfusion of vecuronium $(3 \mathrm{mg} / \mathrm{kg} / \mathrm{h})$ administered through an ear vein. Animals were then intubated and positive pressure ventilated (Bourns BP200, CA); lung tidal volume $(\mathrm{Vt})$, dynamic compliance $\left(C_{\mathrm{dyn}}\right)$, and Oxygenation Index [OI: mean airway pressure $\left(\mathrm{cm} \mathrm{H}_{2} \mathrm{O}\right) \times$ fraction of inspired oxygen $\left.\left(\mathrm{FiO}_{2}\right) / \mathrm{PaO}_{2}(\mathrm{~mm} \mathrm{Hg})\right]$ were monitored by computerized pneumotacography (Chart5 Powerlab, ADI Instr., CO). Continuous three-lead ECG was recorded. The right common carotid flow $\left(Q_{\text {car }}\right)$ was measured by an ultrasonic flow probe (Transonic Systems Inc., NY), as a representation of cerebral blood flow (CBF) (13). Catheters were inserted into femoral arteries to record intraarterial oxygen saturation $\left(\mathrm{SaO}_{2}\right)($ Oximetric System, Abbott Laboratories, IL), mean blood pressure (MBP) (Ominare CMS24, HP, Göblingen, Germany) and take blood samples, and into the right jugular vein to record cardiac output (CO) (PiCCO Plus, Pulsion, München, Germany). Rectal temperature was maintained between 37.5 and $38.5^{\circ} \mathrm{C}$ with heating lamps.
\end{abstract}

Abbreviations: aEEG, amplitude-integrated EEG; CBD, cannabidiol; CBF, cerebral blood flow; CBV, cerebral blood volume; FJB, FluoroJadeB staining; FTOE, fractional tissue oxygenation extraction; HI, hypoxia-ischemia; NIRS, near-infrared spectroscopy; nTHI, normalized total haemoglobin index; OI, oxygenation index; $\boldsymbol{Q}_{\text {car }}$, common carotid artery flow; VEH, vehicle; Vt, lung tidal volume 
Experimental procedures. Hypoxia-ischemia (HI) was induced by clamping both carotid arteries with vascular occluders and lowering $\mathrm{FiO}_{2}$ to $8-10 \%$ over $20 \mathrm{~min}$. Fifteen and $240 \mathrm{~min}$ later, piglets received i.v. $1 \mathrm{~mL}$ of saline (HI+ VEH group, $n=8$, age $4.3 \pm 0.3 \mathrm{~d} \mathrm{~h}$, weight $2.3 \pm 0.2 \mathrm{~kg}$ ) or of a solution containing CBD (Tocris Bioscience, Bristol, UK) $0.1 \mathrm{mg} / \mathrm{kg}$ $(\mathrm{HI}+\mathrm{CBD}, n=8$, age $4.6 \pm 0.3 \mathrm{~d} \mathrm{~h}$, weight $2.1 \pm 0.1 \mathrm{~kg})$. This dose was selected as it was the lowest tested in previous in vivo studies with $\operatorname{CBD}(7,8)$. $\mathrm{CBD}$ was dissolved in emulphor/ethanol/saline 1:1:18 (5). Other piglets were similarly anesthetized and intubated but were kept normoxemic with their carotids unclamped (SHAM, $n=3$, age $4.5 \pm 0.4 \mathrm{~d}$, and weight $2.6 \pm 0.4$ $\mathrm{kg}$ ). Six hours after HI, or the equivalent period in SHAM, the piglets were euthanized with an i.v. injection of potassium chloride. Then, the brain was perfused via the carotid arteries with heparin in cold saline, removed, fixed with $4 \%$ paraformaldehide, and then stored at $4{ }^{\circ} \mathrm{C}$.

Data acquisition and analysis. Physiologic assessment. Deviations from acceptable blood gases values (ABL5, Radiometer, Copenhagen, Denmark) $\left(\mathrm{PaO}_{2} 90-110 \mathrm{~mm} \mathrm{Hg}, \mathrm{PaCO}_{2} 35-45 \mathrm{~mm} \mathrm{Hg}\right.$, and $\mathrm{pH}$ 7.35-7.45) were corrected by changing ventilator parameters and/or by adding sodium bicarbonate or Tris as needed. MBP was maintained over $50 \mathrm{~mm} \mathrm{Hg}$ and blood glucose levels over $40 \mathrm{mg} / \mathrm{dL}$ by administering a perfusion of dopamine $(0.6$ $\mathrm{mg} / \mathrm{mL}$ in $5 \%$ dextrose) or $25 \%$ dextrose, respectively, when needed. Blood samples were collected at baseline and 0,3 , and $6 \mathrm{~h}$ postinsult. Cardiac troponin T (cTnT), a marker of myocardial ischemia, was measured by ELISA (Elecsys Analyzer, Roche Diagnostics, Mannheim, Germany).

Neurophysiological assessment. Tissue oxygen index (TOI) and variations in total $\mathrm{Hb}$ index (THI) were continuously monitored using a NIRSsystem (NIRO-200, Hamamatsu Photonics KK, Joko Cho, Japan). The NIRS sensor was placed on the skull in the midline fronto-parietally and fixed with bandages. TOI represents the tissue oxygen saturation and is measured in percent; it was used to calculate the fractional tissue oxygen extraction (FTOE) (14): $\mathrm{FTOE}=\left(\mathrm{SaO}_{2}-\mathrm{TOI}\right) / \mathrm{SaO}_{2}$. Normalized tissue $\mathrm{Hb}$ index (nTHI) is an absolute figure of the total $\mathrm{Hb}(\mathrm{tHb})$ content in brain (15); its changes from one measuring point to another are measured as a percentage.

Brain activity (integrated amplitude) and impedance were monitored using a two-channel bed EEG monitor (BRM2, BrainZ Instruments, Auckland, New Zealand). The "raw" EEG traces were manually reviewed for seizures (periods of sudden increase in voltage, accompanied by a narrowing of the band of aEEG activity and followed by a brief period of suppression).

Histologic study. Fixed brains were cut into sections $5 \mathrm{~mm}$ in width and embedded in paraffin. Coronal sections $(4 \mu \mathrm{m})$ were cut and mounted on a glass slide to be stained. To assess brain damage, consecutive pairs of brain sections were stained by two different methods (16): First, Nissl staining to determine early neuronal necrosis. Areas of $1 \mathrm{~mm}^{2}$ in the central three lobes of the parietal cortex and in the CA1 area of hippocampus were examined using a light microscope $(\times 400)$ by an investigator blinded to the experimental group, using a grid of 50 compartments, calculating the mean of 5 compartments. Parietal cortex and hippocampus are known to be particularly sensitive to HI-induced tissue damage $(17,18)$; both were counted at $3.00 \mathrm{~mm}$ in the posterior plane, as shown in a stereotaxic atlas of pig brain (19). Apparently normal neurons were morphologically identified by the presence of typical nuclei with clear nucleoplasm and a distinct nucleolus, surrounded by purple-stained cytoplasm. Neurons were defined as damaged when no distinction could be made between nucleus and cytoplasm (pyknotic or necrotic). Second, to determine the presence of degenerating neurones, brain sections were stained with FluoroJade B (FJB) (16); these sections were examined using a fluorescence microscope (I3 filter cube for an FITC, excitation band of $450-490 \mathrm{~nm}$ ).

Statistical analysis. SPSS 11.0.0 was used for all statistical analyses. Mean values have been compared using the Kruskal-Wallis test for unpaired data and the Wilcoxon signed rank test for paired data. Bonferroni correction for multiple testing was performed when appropriate. A $p$ value $<0.05$ was considered to be significant. All data are presented as means \pm SE.

\section{RESULTS}

Neurophysiological assessment. Hypoxic-ischemic insult induced a hyperaemic response in brain circulation, as shown by the dramatic increase of $Q_{\text {car }}$ (Fig. 1A). Afterward, $Q_{\text {car }}$ remained stable and similar to SHAM. Similarly, an increase of nTHI just after the HI insult was observed by NIRS (Fig. $1 B)$. In HI+CBD, nTHI returned to baseline in approximately $30 \mathrm{~min}$, then remaining similar to SHAM, whereas in $\mathrm{HI}+\mathrm{VEH}$, nTHI remained higher than SHAM. In contrast,
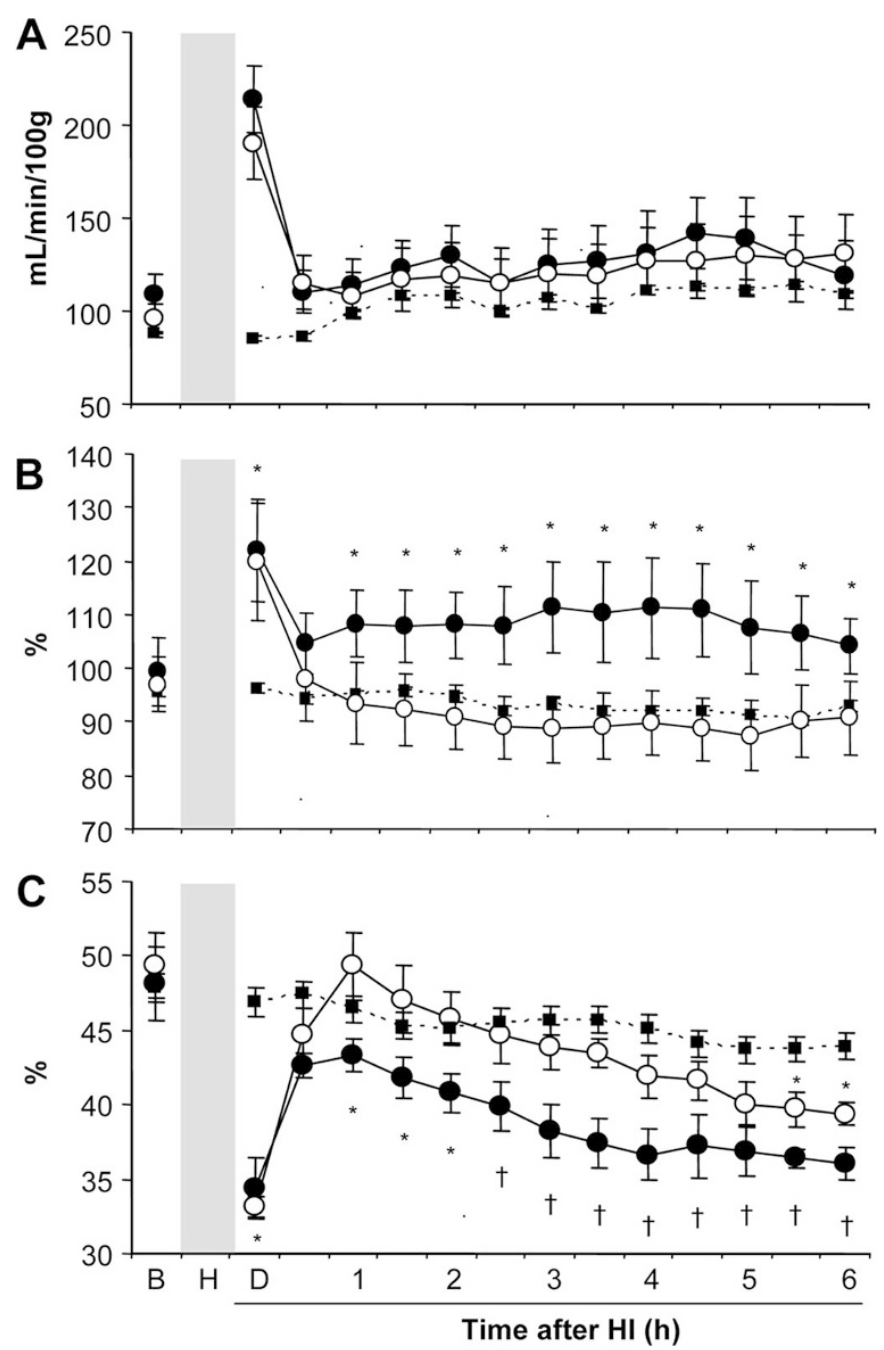

Figure 1. Cerebral hemodynamic and metabolic changes induced by $\mathrm{HI}$ in piglets and its modification by postinsult administration of cannabidiol 0.1 $\mathrm{mg} / \mathrm{kg}$ i.v. $A$, changes in carotid blood flow; $B$, changes in nTHI determined by NIRS; $C$, changes in FTOE calculated from NIRS. VEH $(-)$ : HI piglets treated with vehicle $(n=8)$. CBD $(\bigcirc)$ : HI piglets treated with cannabidiol $(n=8)$. SHAM $(\square)$ : operated piglets without HI. B: baseline. H: HI insult. D: drug administration. (*) Kruskall-Wallis $p<0.05$ vs SHAM; $(\dagger)$ KruskallWallis $p<0.05 v s$ VEH.

FTOE fell dramatically during HI, subsequently rising again in the first hour postinsult (Fig. 1C). In $\mathrm{HI}+\mathrm{CBD}$, FTOE reached values similar to SHAM during the first $3 \mathrm{~h}$, slightly decreasing afterward; in HI+VEH, in contrast, FTOE remained significantly lower than SHAM from the end of HI and lower than $\mathrm{HI}+\mathrm{CBD}$ from $1 \mathrm{~h}$ postinsult.

During HI, EEG amplitude was reduced to $14.5 \pm 4.3 \%$ and $16.9 \pm 2.3 \%$ baseline in $\mathrm{HI}+\mathrm{VEH}$ and $\mathrm{HI}+\mathrm{CBD}$, respectively (Fig. 2A). This severely depressed activity remained unchanged in $\mathrm{HI}+\mathrm{VEH}$ but partially recovered from $1 \mathrm{~h}$ postinsult in $\mathrm{HI}+\mathrm{CBD}$ (Fig. 2A); thus, at the end of the experiment, amplitude was $20.5 \pm 4.8 \%$ and $46.4 \pm 7.8 \%$ baseline in $\mathrm{HI}+\mathrm{VEH}$ and $\mathrm{HI}+\mathrm{CBD}$, respectively $(p<0.05)$. None of $\mathrm{HI}+\mathrm{VEH}$ regained an EEG amplitude over $4 \mu \mathrm{V}$, whereas that amplitude was regained in $6 / 8 \mathrm{HI}+\mathrm{CBD}(p<0.05)$. The EEG traces indicate the presence of seizures in all piglets from $\mathrm{HI}+\mathrm{VEH}$ but only in $4 / 8 \mathrm{HI}+\mathrm{CBD}(p<0.05)$. 

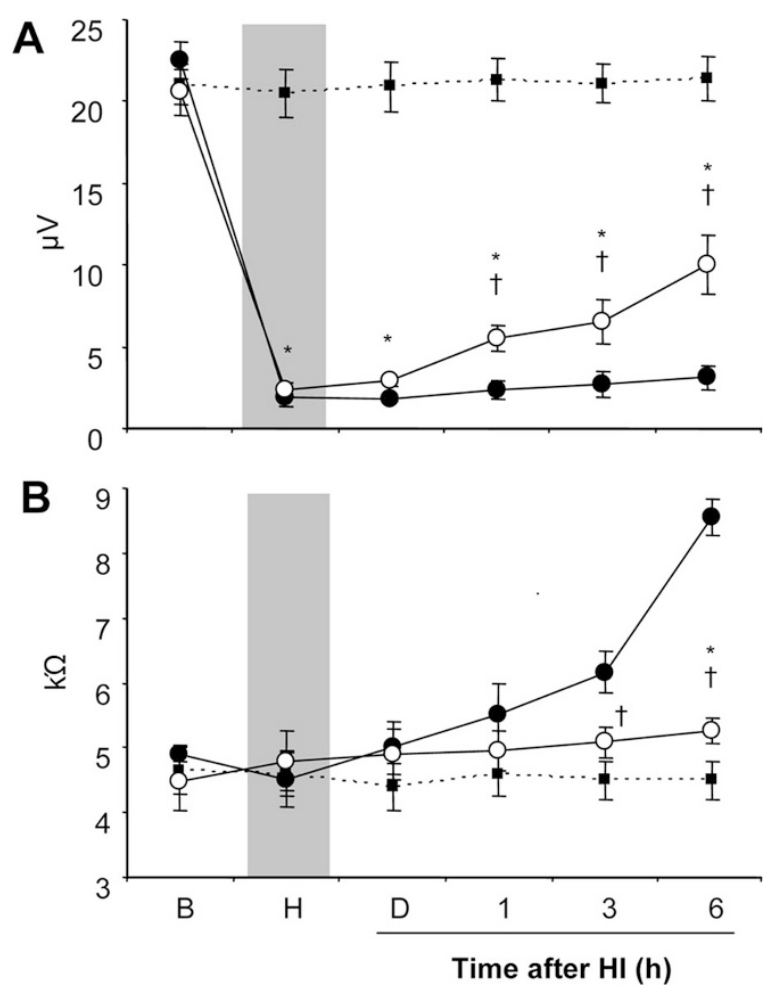

Figure 2. Changes in cerebral amplitude $(A)$ and impedance $(B)$ induced by $\mathrm{HI}$ in piglets and its modification by postinsult administration of cannabidiol $0.1 \mathrm{mg} / \mathrm{kg}$ i.v., determined by amplitude-integrated EEG. VEH $(\bullet)$ : HI piglets treated with vehicle $(n=8)$. CBD $(\bigcirc)$ : HI piglets treated with cannabidiol $(n=8)$. SHAM ( $\square)$ : operated piglets without HI. B: baseline. H: HI insult. D: drug administration. (*) Kruskall-Wallis $p<0.05$ vs SHAM; (†) KruskallWallis $p<0.05$ vs VEH.

Cerebral impedance increased $1 \mathrm{~h}$ postinsult in $\mathrm{HI}+\mathrm{VEH}$, reaching values 2 -fold higher than baseline (Fig. $2 B$ ); in $\mathrm{HI}+\mathrm{CBD}$, the increase of impedance was very modest and only significantly different from SHAM at the end of the experiment (Fig. 2B).

Histologic analysis. Nissl staining revealed a decrease in the number of apparently normal neurons in cortex and hippocampus of $\mathrm{HI}+\mathrm{VEH}$ piglets (Fig. 3) $\left(371 \pm 21\right.$ per $\mathrm{mm}^{2}$ in cortex and $82 \pm 27$ per $\mathrm{mm}^{2}$ in hippocampus versus $653 \pm 6$ per $\mathrm{mm}^{2}$ and $240 \pm 5$ per $\mathrm{mm}^{2}$, respectively, in SHAM, both $p<0.05$ ). In addition, a number of pyknotic neurons appeared in $\mathrm{HI}+\mathrm{VEH}$, mainly in the deeper layers of cortex but also in hippocampus. In $\mathrm{HI}+\mathrm{CBD}$, the loss of normal neurons was blunted and the appearance of pyknotic cells prevented (Fig. 3 ); thus, normal neurons were $482 \pm 21$ per $\mathrm{mm}^{2}$ in cortex and $160 \pm 25$ per $\mathrm{mm}^{2}$ in hippocampus in $\mathrm{HI}+\mathrm{CBD}(p<0.05$ versus $\mathrm{HI}+\mathrm{VEH}$ and versus $\mathrm{SHAM})$. FJB staining revealed the appearance of a number of degenerating neurons in HI+VEH in cortex and hippocampus (Fig. 4) $(298 \pm 29$ per $\mathrm{mm}^{2}$ in cortex and $260 \pm 44$ per $\mathrm{mm}^{2}$ in hippocampus, versus $10 \pm 3$ per $\mathrm{mm}^{2}$ in cortex and $5 \pm 2$ per $\mathrm{mm}^{2}$ in hippocampus in SHAM, both $p<0.05)$. The number of degenerating neurons was reduced by CBD $\left(96 \pm 21\right.$ per $\mathrm{mm}^{2}$ in cortex and $116 \pm 23$ per $\mathrm{mm}^{2}$ in hippocampus in $\mathrm{HI}+\mathrm{CBD}, p<0.05$ versus $\mathrm{HI}+\mathrm{VEH}$ and versus $\mathrm{SHAM}$ ).

Physiologic data. Blood pressure fell after HI, more severely in $\mathrm{HI}+\mathrm{VEH}$ than in $\mathrm{HI}+\mathrm{CBD}$ (Table 1) even though

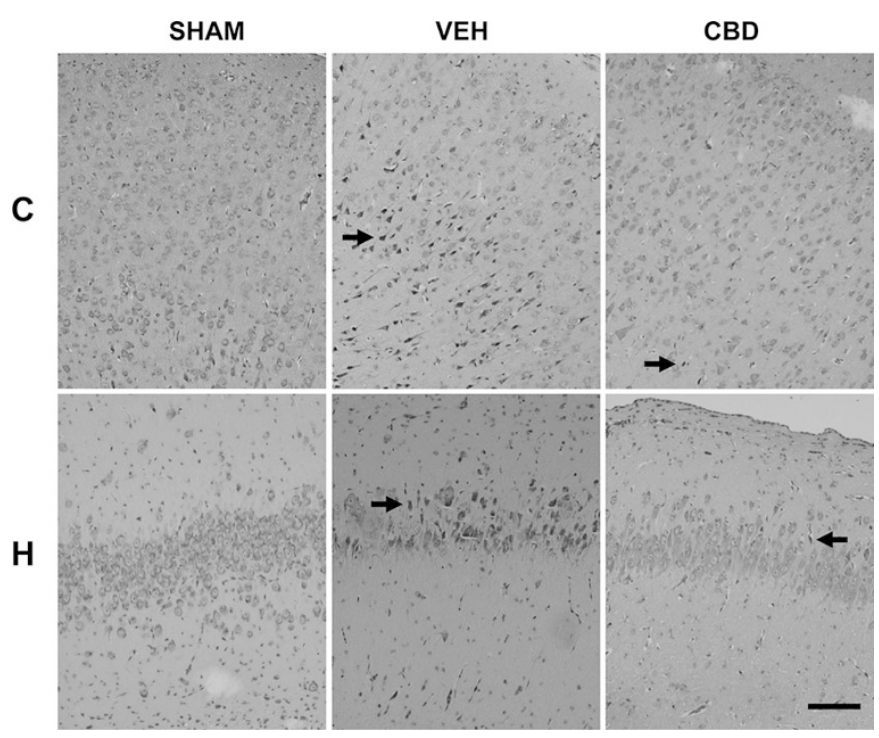

Figure 3. Representative light microphotographs of Nissl-stained brain sections, obtained after sham operation (SHAM) or after HI from piglets receiving VEH or CBD $0.1 \mathrm{mg} / \mathrm{kg}$. C: parietal cortex; H: hippocampus. In brain from $\mathrm{HI}+\mathrm{VEH}$ there is a decrease in number of viable neurons and an increase in number of pyknotic cells (arrows). Administration of CBD reduced the loss of viable neurons and the presence of pyknotic cells. Original magnification $\times 200$, bar: $100 \mu \mathrm{m}$.

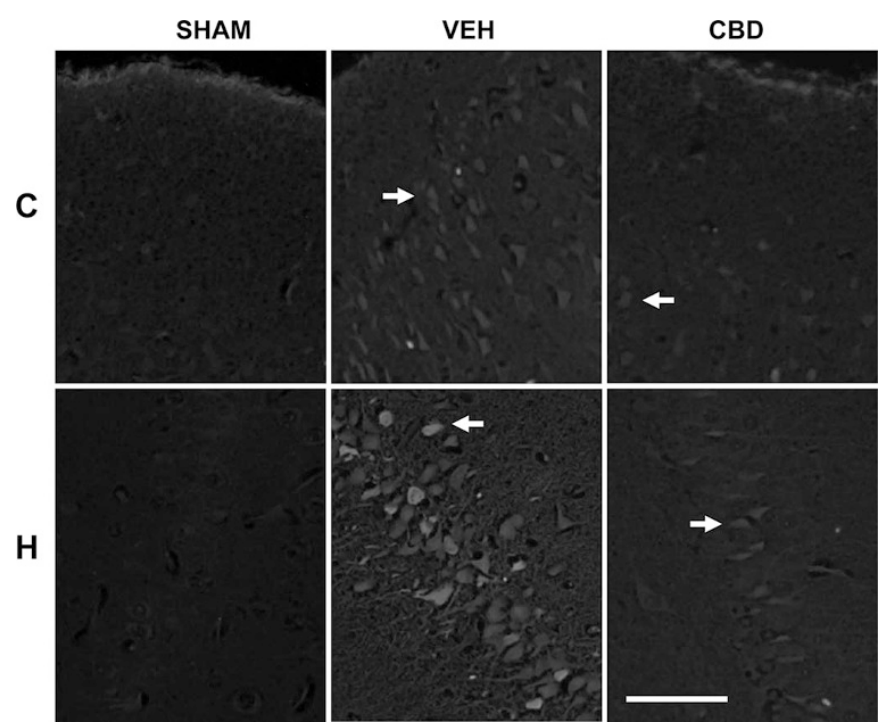

Figure 4. Representative light microphotographs of FluoroJade B stained brain sections, obtained after sham operation (SHAM) or after HI from piglets receiving VEH or CBD $0.1 \mathrm{mg} / \mathrm{kg}$. C: parietal cortex; H: hippocampus. Administration of CBD reduced the number of degenerating-FJB-stainedcells. Original magnification $\times 200$, bar: $100 \mu \mathrm{m}$.

the former were receiving at the end of the experiment more dopamine than the latter $(16.9 \pm 3.8 \mu \mathrm{g} / \mathrm{kg} / \mathrm{min}$ versus $8.1 \pm$ $2.2 \mu \mathrm{g} / \mathrm{kg} / \mathrm{min}, p<0.05$ ). Decrease of MBP was compensated for by a significant increase in heart rate, to maintain $\mathrm{CO}$ stable (Table 1). cTnT was undetectable in SHAM and in the other groups at baseline. HI led to an immediate and sustained increase in cTnT that was greater in VEH than in CBD, so that from $3 \mathrm{~h}$ after HI cTnT levels were greater in VEH than in CBD (Table 1).

$\mathrm{HI}$ led to a similar decrease of $\mathrm{PaO}_{2}$ in $\mathrm{HI}+\mathrm{VEH}$ and $\mathrm{HI}+\mathrm{CBD}(31.1 \pm 2.5$ and $28.9 \pm 1.6 \mathrm{~mm} \mathrm{Hg}$, respectively). 
Table 1. Results from physiological monitoring

\begin{tabular}{|c|c|c|c|c|}
\hline & \multicolumn{4}{|c|}{ Time after HI } \\
\hline & B & $\mathrm{D}$ & $3 \mathrm{~h}$ & $6 \mathrm{~h}$ \\
\hline \multicolumn{5}{|c|}{ Hemodynamic } \\
\hline \multicolumn{5}{|c|}{$\mathrm{CO}$} \\
\hline $\mathrm{S}$ & $1.22(0.15)$ & $1.18(0.14)$ & $1.35(0.17)$ & $1.38(0.20)$ \\
\hline $\mathrm{V}$ & $1.15(0.14)$ & $0.99(0.06)$ & $1.20(0.18)$ & $1.28(0.15)$ \\
\hline $\mathrm{C}$ & $1.00(0.10)$ & $1.10(0.11)$ & $1.08(0.13)$ & $1.14(0.14)$ \\
\hline \multicolumn{5}{|c|}{ MBP } \\
\hline $\mathrm{S}$ & $94.3(5.4)$ & $88.7(3.2)$ & $80.3(2.7)^{*}$ & $78.8(3.6)^{*}$ \\
\hline $\mathrm{V}$ & $85.9(2.8)$ & $83.1(3.1)$ & $64.1(2.1)$ & $59.7(2.1) \dagger$ \\
\hline $\mathrm{C}$ & $89.8(4.1)$ & $79.0(2.5)$ & $64.0(2.7)$ & $64.8(2.5)^{* \dagger}$ \\
\hline \multicolumn{5}{|l|}{ HR } \\
\hline $\mathrm{S}$ & $243(6)$ & 237 (12) & $221(11)$ & $217(5)$ \\
\hline V & 237 (12) & 257 (10) & $252(12) \dagger$ & $245(10) \dagger$ \\
\hline $\mathrm{C}$ & $235(12)$ & $257(10)$ & $242(8) \dagger$ & $236(10) \dagger$ \\
\hline \multicolumn{5}{|c|}{ cTnT } \\
\hline $\mathrm{S}$ & - & - & - & - \\
\hline $\mathrm{V}$ & - & $0.012(0.002)$ & $0.145(0.03)$ & $0.126(0.02)$ \\
\hline $\mathrm{C}$ & - & $0.022(0.004)^{*}$ & $0.084(0.02)^{*}$ & $0.095(0.02)^{*}$ \\
\hline \multicolumn{5}{|c|}{ Blood gases } \\
\hline $\mathrm{S}$ & $7.36(0.01)$ & $7.41(0.01)$ & $7.39(0.01)^{*}$ & $7.40(0.02)$ \\
\hline V & $7.33(0.01)$ & $7.22(0.03) \dagger$ & $7.31(0.02) \dagger$ & $7.39(0.02)$ \\
\hline $\mathrm{C}$ & $7.33(0.03)$ & $7.26(0.03) \dagger$ & $7.43(0.02)^{*}$ & $7.40(0.02)$ \\
\hline \multicolumn{5}{|l|}{$\mathrm{PaO}_{2}$} \\
\hline $\mathrm{S}$ & $99.6(1.3)$ & $101.8(3.1)$ & $102.3(4.3)$ & $96.3(2.5)$ \\
\hline $\mathrm{V}$ & $104.5(4.1)$ & $104.8(2.6)$ & $105.6(5.9)$ & $102.4(4.5)$ \\
\hline $\mathrm{C}$ & $101.4(3.1)$ & 99.7 (3.8) & $103.4(5.1)$ & $100.1(2.9)$ \\
\hline \multicolumn{5}{|c|}{$\mathrm{PaCO}_{2}$} \\
\hline S & 39.7 (1.0) & $36.3(2.2)$ & $40.6(1.2)^{*}$ & $43(0.5)^{*}$ \\
\hline $\mathrm{V}$ & $40.1(1.6)$ & $52.2(5.7) \dagger$ & $48.7(2.7) \dagger$ & $50.2(3.1) \dagger$ \\
\hline $\mathrm{C}$ & $42.5(2.2)$ & $47.6(4.9) \dagger$ & $36.8(3.1)^{*}$ & $41.8(1.9)^{*}$ \\
\hline \multicolumn{5}{|c|}{ Respiratory } \\
\hline \multicolumn{5}{|l|}{ OI } \\
\hline S & $12.2(1.3)$ & 11.4 (1.6) & $14.6(1.7)$ & $16.9(1.7)^{*}$ \\
\hline $\mathrm{V}$ & $13.6(2.2)$ & $15.6(2.0) \dagger$ & $16.1(1.9)$ & $20.2(1.8) \dagger$ \\
\hline $\mathrm{C}$ & $15.5(2.4)$ & $17.8(1.9) \dagger$ & $14.6(1.4)$ & $13.6(1.5)^{* \dagger}$ \\
\hline \multicolumn{5}{|l|}{$\mathrm{Vt}$} \\
\hline $\mathrm{S}$ & $7.1(0.2)$ & $6.9(0.5)$ & $6.6(0.5)$ & $6.1(0.5)$ \\
\hline $\mathrm{V}$ & $7.2(0.2)$ & $6.9(0.4)$ & $7.1(0.4)$ & $6.6(0.4)$ \\
\hline $\mathrm{C}$ & $7.5(0.4)$ & $7.0(0.5)$ & $7.4(0.4)$ & $7.8(0.4)^{* \dagger}$ \\
\hline \multicolumn{5}{|l|}{$C_{\mathrm{dyn}}$} \\
\hline$S$ & $1.05(0.02)$ & $1.02(0.06)$ & $1.00(0.10)$ & $0.91(0.03)$ \\
\hline V & $1.12(0.09)$ & $1.10(0.04)$ & $1.03(0.04)$ & $0.88(0.04)$ \\
\hline $\mathrm{C}$ & $1.07(0.10)$ & $1.06(0.06)$ & $1.09(0.05)$ & $1.12(0.08)^{* \dagger}$ \\
\hline
\end{tabular}

$*$ ANOVA $p<0.05 v s \mathrm{~V} ; \dagger$ ANOVA $p<0.05 v s \mathrm{~S}$.

Results as mean (ESM). S: sham operated piglets; V: asphyxiated piglets treated with vehicle; $\mathrm{C}$ : asphyxiated piglets treated with cannabidiol; B: basal; D: drug administration (vehicle or cannabidiol $0.1 \mathrm{mg} / \mathrm{kg}$, i.v.; $15 \mathrm{~min}$ after $\mathrm{HI})$.

CO: cardiac output (L/min); MBP: mean blood pressure (mm $\mathrm{Hg}$ ); HR: heart rate (beats per minute); cTnT: cardiac troponin (ng/mL); OI: oxygenation index = mean airway pressure $\left(\mathrm{cm} \mathrm{H}_{2} \mathrm{O}\right) \times \mathrm{FiO}_{2} /$ arterial $\mathrm{PO}_{2}$; Vt: tidal volume $(\mathrm{mL} / \mathrm{kg}) ; C_{\mathrm{dyn}}$ : ratio of dynamic lung compliance.

$\mathrm{HI}$ insult induced a profound decrease in $\mathrm{pH}$, similar in $\mathrm{HI}+\mathrm{VEH}$ and $\mathrm{HI}+\mathrm{CBD}$ (Table 1). In all $\mathrm{HI}+\mathrm{CBD}$ piglets, normal $\mathrm{pH}$ was regained by $1 \mathrm{~h}$ postinsult; in $\mathrm{HI}+\mathrm{VEH}$, normal $\mathrm{pH}$ was regained only in six of eight piglets beyond $3 \mathrm{~h}$ postinsult. Similarly, $\mathrm{PaCO}_{2}$ increased after $\mathrm{HI}$ in both groups (Table 1); HI $+\mathrm{CBD}$ regained normal levels by $2 \mathrm{~h}$ postinsult whereas in $\mathrm{HI}+\mathrm{VEH}$, five of eight piglets were still showing supra-normal values at the end of the experiment.

The HI insult led to an early increase of $\mathrm{O}_{2}$ needs, as demonstrated by the enhancement of $\mathrm{OI}$ in both $\mathrm{HI}$ groups
(Table 1). Mechanical ventilation induced lung damage, as suggested even in SHAM animals by the progressive increase of $\mathrm{OI}$ and decrease of $\mathrm{Vt}$ and compliance (Table 1). CBD demonstrated some lung protective effects, as both Vt and compliance remained stable throughout the experiment, unlike $\mathrm{HI}+\mathrm{VEH}$ piglets, which showed a decrease of both parameters parallel to that observed in CTL animals. Moreover, OI decreased during the experimental period in $\mathrm{HI}+\mathrm{CBD}$ to values even lower than in SHAM, whereas in HI+VEH OI values increased to reach statistical significance at the end of the experiment.

\section{DISCUSSION}

Our present investigation demonstrated that CBD, administered after $\mathrm{HI}$ in newborn piglets, could display neuroprotective activity without inducing significant side effects. To the best of our knowledge, this is the first study demonstrating short-term neuroprotection by CBD in newborn animals, and supports previous studies in adult rodent models of stroke $(5,7,8)$. Importantly, CBD protected against ischemic brain injury when administered after the insult, which renders CBD a feasible tool for clinical use, as NHIE is currently unpredictable (20). Another point favoring a possible clinical use of CBD is its lack of psychoactive effects because CBD does not activate $\mathrm{CB}_{1}$ receptors (6). In our study, $\mathrm{CBD}$ was neuroprotectant at a dose $(0.1 \mathrm{mg} / \mathrm{kg})$ below that reported for adult rodents $(1-5 \mathrm{mg} / \mathrm{kg})(5,7,8)$. This difference might be due to species- or age-related differences in sensitivity to CBD and/or to the use of a different route for drug. The absence of significant side effects with CBD in our study does, however, warrant further investigation directed at examining the effects of higher doses of this cannabinoid.

After the HI episode, we did not observe any difference in $Q_{\text {car }}$ between SHAM and HI+VEH piglets, as reported previously (21), nor between HI+VEH and HI + CBD. Previous studies indicate that CBD increases $\mathrm{CBF}$ in cortex during ischemia in mice (7), an effect that may reflect the ability of CBD to dilate cerebral arteries in rodents via the activation of vanilloid receptors (6). This difference might be due to the low dose of CBD we used, as CBD has been demonstrated to be a full vanilloid receptor agonist at concentrations attained after its administration at doses almost 100 times higher (22). Nevertheless, changes in regional CBF by CBD cannot be ruled out in our experiments, as we measured $Q_{\text {car }}$. In NIRS, $\mathrm{HI}+\mathrm{VEH}$ showed an increase in nTHI. nTHI provides an absolute measure of $\mathrm{tHb}$ in brain (15), changes in which reflect changes in cerebral blood volume (CBV) (13). Increased CBV may indicate pronounced vasodilation in cerebral microcirculation due to exhausted autoregulatory vasodilation $(14,23)$. Another factor influencing the increase in THI is the increase in oxygenated $\mathrm{Hb}$ content that results from decreased cerebral oxygen utilization caused by increased brain damage (24). Accordingly, FTOE was decreased in HI+ VEH piglets, as reported previously (14). The association of an increase in CBV and a decrease in uptake of oxygen by the brain is considered as particularly ominous for asphyxiated newborns (23). Administration of CBD prevented that increase in THI to 
occur and blunted the decrease of FTOE. Normal CBV together with increased uptake of oxygen by the brain reflects less severe cerebral hemodynamic impairment in human newborns and is associated with a more favorable outcome (23).

The pattern of aEEG in piglets after HI resembles best the situation in the human newborn affected by perinatal asphyxia (12). The immediate drop in amplitude we observed at the start of the HI period, similar in VEH and CBD, reflects the severity of the insult $(13,25)$ and is due to the decrease in neuronal metabolism that protects the brain cells against further injury (12). Sustained severely reduced EEG amplitude despite oxygenation and hemodynamic recovery, as we observed in $\mathrm{HI}+\mathrm{VEH}$, suggests neuronal hypofunction with lower brain oxygen utilization $(12,13)$. This agrees with the low FTOE we observed during this period in HI+VEH. None of $\mathrm{HI}+\mathrm{VEH}$ piglets did recover EEG amplitude over $4 \mu \mathrm{V}$ and all of them showed seizure activity, both effects that signal an unfavourable outcome in human newborns $(26,27)$. In contrast, CBD administration led to a significant recovery of amplitude, with six of eight piglets regaining EEG amplitude by more than $4 \mu \mathrm{V}$ at the end of the experiment. Improvement in aEEG pattern is considered a good predictor of favorable outcome in newborns (26). In addition, only half of HI+CBD piglets had significant seizures; a similar reduction of seizures occurs in HI piglets in response to high doses of the anticonvulsant topiramate (18). This finding is in line with previous reports that $\mathrm{CBD}$ is an anticonvulsant (6).

Finally, EEG studies also demonstrated a dramatic postinsult increase in impedance in $\mathrm{HI}+\mathrm{VEH}$, which indicates the presence of cerebral edema (28). Impedance increase starts as early as $10 \mathrm{~min}$ postHI and is strongly associated with poor neurologic outcome (28). Administration of CBD blunted this progressive increase in impedance. Progressing edema indicates a failure in brain capacity to reestablish cellular homoeostasis (28), being known as cytotoxic edema (20). Antiedema activity has been described for other cannabinoids after close brain injury (1), but to the best of our knowledge, no data on CBD exist.

The neuroprotective effect of CBD was confirmed by histology. In HI+VEH, the viable cell count was reduced to 57 and 34\% of SHAM in cortex and hippocampus, respectively. Administration of CBD reduced HI-induced viable cell loss by $60 \%$ in cortex and by $50 \%$ in hippocampus. Also, CBD reduced the number of neurones undergoing degeneration in response to $\mathrm{HI}$, as indicated by FJB staining; CBD administration reduced the number of FJB-positive cells observed after HI by $78 \%$ in cortex and $56 \%$ in hippocampus. Similar histologic protective effects have been reported in HI piglets treated with high-dose topiramate (18), but not with other neuroprotective substances such as the antioxidants deferoxamine or allopurinol (17).

We did not detect any side effects in piglets treated with $\mathrm{CBD}$, supporting that $\mathrm{CBD}$ is essentially nontoxic and free from short- or long-term side effects (5-9). CBD at doses up to $5 \mathrm{mg} / \mathrm{kg}$ does not induce changes in blood pressure or ventilatory parameters in rodents $(8,29)$, whereas in artificially ventilated anesthetized adult dogs CBD $1 \mathrm{mg} / \mathrm{kg}$ i.v decreases lung compliance and $\mathrm{CO}$ (6). Possibly because of the low dose of CBD used in our experiments or because of species- or age-related differences in extracerebral sensitivity to CBD, no negative hemodynamic or ventilatory effects were observed in $\mathrm{HI}+\mathrm{CBD}$. Instead, we observed significant beneficial extra cerebral effects. After HI, arterial $\mathrm{pH}$ fell because of poor peripheral circulation (20), returning to normal $3 \mathrm{~h}$ postinsult as reported previously (21). Normalization of arterial $\mathrm{pH}$ was quicker in $\mathrm{HI}+\mathrm{CBD}$, suggesting a beneficial effect of CBD on systemic circulation. This is supported by our finding that the dose of dopamine needed in $\mathrm{HI}+\mathrm{CBD}$ to maintain MBP was less than half of that required in HI+VEH. In addition, CBD showed cardioprotective effects, as suggested by its effect on cTnT levels, a marker of myocardial damage after HI (20). Although myocardial ischemia was greater in the CBD than the VEH group, as indicated by the higher cTnT levels at drug administration, CBD blunted subsequent rises of cTnT at both $3 \mathrm{~h}$ and $6 \mathrm{~h}$ after HI. Protective effects of CBD against myocardial ischemic reperfusion injury have also been detected in adult rats (30). Mechanical ventilation progressively damaged piglet lung, as shown by the decrease in lung compliance observed in SHAM piglets throughout the experiment; a similar decrease was observed in $\mathrm{HI}+\mathrm{VEH}$. In $\mathrm{HI}+\mathrm{CBD}$, in contrast, lung compliance remained stable and Vt improved throughout the experiment. Although we did not analyze lung tissue because this was not an endpoint of the study, this effect of CBD could be attributed to its robust antiinflammatory effect (6). Thus, in HI+VEH, there was both a progressive increase in the OI, indicating a progressive impairment of oxygenation, and an increase in $\mathrm{PaCO}_{2}$, indicating an impairment of ventilation. Consequently, it is likely that after HI, gas diffusion in the lung decreased over time, that this decrease occurred because the alveolar wall became progressively damaged by inflammation (31) and that CBD acted to reduce this inflammation. It is worth noting, however, that despite the aforementioned differences, hemodynamic or gasometrical parameters in $\mathrm{HI}+\mathrm{VEH}$ and $\mathrm{HI}+\mathrm{CBD}$ did not reach values known to modify CBF (20). Thus, these differences are unlikely to have a decisive influence on the neuroprotective effect of CBD.

In conclusion, administration of CBD after a $\mathrm{HI}$ insult in newborn piglets reduced short-term brain damage, in a manner that can be attributed to a CBD-induced reduction of cerebral hemodynamic impairment, improvement of brain metabolic activity postinsult, reduction of brain edema, and reduction of seizures. These neuroprotective effects were not only free from side effects but also associated with some cardiac, hemodynamic, and ventilatory benefits. Consequently, because other promising compounds with neuroprotective activity that have been tested in animals, for example topiramate or erythropoietin, have not displayed such extracerebral benefits $(18,32)$, and because the simplicity and feasibility of administering CBD in the clinic has apparent advantages over more sophisticated and complex strategies such as hypothermia, we consider CBD to be a serious candidate for future clinical trials with asphyxiated newborns. However, before any clinical trials with humans are performed, it will be important to perform further experiments with piglets to establish an opti- 
mal dosing regimen for CBD and to characterize its long-term effects.

Acknowledgments. The authors thank Carolina Herranz for excellent technical assistance.

\section{REFERENCES}

1. Mechoulam R, Panikashvili D, Shohami E 2002 Cannabinoids and brain injury: therapeutic implications. Trends Mol Med 8:58-61

2. Nagayama T, Sinor AD, Simon RP, Chen J, Graham SH, Jin K, Greenberg DA 1999 Cannabinoids and neuroprotection in global and focal cerebral ischemia and in neuronal cultures. J Neurosci 19:2987-2995

3. Fernandez-Lopez D, Martinez-Orgado J, Nunez E, Romero J, Lorenzo P, Moro MA, Lizasoain I 2006 Characterization of the neuroprotective effect of the cannabinoid agonist WIN-55212 in an in vitro model of hypoxic-ischemic brain damage in newborn rats. Pediatr Res 60:169-173

4. Fernandez-Lopez D, Pazos MR, Tolon RM, Moro MA, Romero J, Lizasoain I, Martinez-Orgado J 2007 The cannabinoid agonist WIN55212 reduces brain damage in an in vivo model of hypoxic-ischemic encephalopathy in newborn rats. Pediatr Res 62:255-260

5. Braida D, Pegorini S, Arcidiacono MV, Consalez GG, Croci L, Sala M 2003 Post-ischemic treatment with cannabidiol prevents electroencephalographic flattening, hyperlocomotion and neuronal injury in gerbils. Neurosci Lett 346:61-64

6. Pertwee RG 2004 The pharmacology and therapeutic potential of cannabidiol. In: Di Marzo V (ed) Cannabinoids. Kluwer Academic/Plenum Publishers, New York, pp. 32-83

7. Mishima K, Hayakawa K, Abe K, Ikeda T, Egashira N, Iwasaki K, Fujiwara M 2005 Cannabidiol prevents cerebral infarction via a serotonergic 5-hydroxytryptamine1A receptor-dependent mechanism. Stroke 36:1077-1082

8. Hayakawa K, Mishima K, Nozako M, Hazekawa M, Irie K, Fujioka M, Orito K, Abe K, Hasebe N, Egashira N, Iwasaki K, Fujiwara M 2007 Delayed treatment with cannabidiol has a cerebroprotective action via a cannabinoid receptor-independent myeloperoxidase-inhibiting mechanism. J Neurochem 102:1488-1496

9. Mechoulam R, Peters M, Murillo-Rodriguez E, Hanus LO 2007 Cannabidiolrecent advances. Chem Biodivers 4:1678-1692

10. Marsicano G, Moosmann B, Hermann H, Lutz B, Behl C 2002 Neuroprotective properties of cannabinoids against oxidative stress: role of the cannabinoid receptor CB1. J Neurochem 80:448-456

11. Esposito G, De Filippis D, Maiuri MC, De Stefano D, Carnuccio R, Iuvone T 2006 Cannabidiol inhibits inducible nitric oxide synthase protein expression and nitric oxide production in beta-amyloid stimulated PC12 neurons through p38 MAP kinase and NF-kappaB involvement. Neurosci Lett 399:91-95

12. Ioroi T, Peeters-Scholte C, Post I, Leusink C, Groenendaal F, van Bel F 2002 Changes in cerebral haemodynamics, regional oxygen saturation and amplitudeintegrated continuous EEG during hypoxia-ischaemia and reperfusion in newborn piglets. Exp Brain Res 144:172-177

13. Gavilanes AW, Vles JS, von Siebenthal K, Reulen JP, Nieman FH, van Sprundel R, Blanco CE 2001 Electrocortical brain activity, cerebral haemodynamics and oxygenation during progressive hypotension in newborn piglets. Clin Neurophysiol 112:52-59

14. Toet MC, Lemmers PM, van Schelven LJ, van Bel F 2006 Cerebral oxygenation and electrical activity after birth asphyxia: their relation to outcome. Pediatrics 117:333-339
15. Nagdyman N, Fleck TP, Ewert P, Abdul-Khaliq H, Redlin M, Lange PE 2003 Cerebral oxygenation measured by near-infrared spectroscopy during circulatory arrest and cardiopulmonary resuscitation. Br J Anaesth 91:438-442

16. Martinez-Orgado J, Fernandez-Frutos B, Gonzalez R, Romero E, Uriguen L, Romero J, Viveros MP 2003 Neuroprotection by the cannabinoid agonist WIN-55212 in an in vivo newborn rat model of acute severe asphyxia. Brain Res Mol Brain Res 114:132-139

17. Peeters-Scholte C, Braun K, Koster J, Kops N, Blomgren K, Buonocore G, BuulOffers S, Hagberg H, Nicolay K, van Bel F, Groenendaal F 2003 Effects of allopurinol and deferoxamine on reperfusion injury of the brain in newborn piglets after neonatal hypoxia-ischemia. Pediatr Res 54:516-522

18. Schubert S, Brandl U, Brodhun M, Ulrich C, Spaltmann J, Fiedler N, Bauer R 2005 Neuroprotective effects of topiramate after hypoxia-ischemia in newborn piglets. Brain Res 1058:129-136

19. Felix B, Leger ME, Albe-Fessard D, Marcilloux JC, Rampin O, Laplace JP 1999 Stereotaxic atlas of the pig brain. Brain Res Bull 49:1-137

20. Volpe JJ 2001 Hypoxic-ischemic encephalopathy: clinical aspects. In: Volpe JJ (ed) Neurology of the Newborn. WB Saunders Co, Philadelphia, pp 331-394

21. Tichauer KM, Brown DW, Hadway J, Lee TY, St Lawrence K 2006 Near-infrared spectroscopy measurements of cerebral blood flow and oxygen consumption following hypoxia-ischemia in newborn piglets. J Appl Physiol 100:850-857

22. Bisogno T, Hanus L, De Petrocellis L, Tchilibon S, Ponde DE, Brandi I, Moriello AS, Davis JB, Mechoulam R, Di Marzo V 2001 Molecular targets for cannabidiol and its synthetic analogues: effect on vanilloid VR1 receptors and on the cellular uptake and enzymatic hydrolysis of anandamide. Br J Pharmacol 134:845-852

23. Derdeyn CP, Videen TO, Yundt KD, Fritsch SM, Carpenter DA, Grubb RL, Powers WJ 2002 Variability of cerebral blood volume and oxygen extraction: stages of cerebral haemodynamic impairment revisited. Brain 125:595-607

24. Peeters-Scholte C, van den Tweel E, Ioroi T, Post I, Braun K, Veldhuis W, Nicolay $\mathrm{K}$, Groenendaal F, van Bel F 2002 Pharmacological interventions in the newborn piglet in the first $24 \mathrm{~h}$ after hypoxia-ischemia. A hemodynamic and electrophysiological perspective. Exp Brain Res 147:200-208

25. Gavilanes AW, Vles JS, von Siebenthal K, van Sprundel R, Reulen JP, Blanco CE 2004 Neonatal electrocortical brain activity and cerebral tissue oxygenation during non-acidotic, normocarbic and normotensive graded hypoxemia. Clin Neurophysiol 115:282-288

26. Shah DK, Lavery S, Doyle LW, Wong C, McDougall P, Inder TE 2006 Use of 2-channel bedside electroencephalogram monitoring in term-born encephalopathic infants related to cerebral injury defined by magnetic resonance imaging. Pediatrics 118:47-55

27. Toet MC, Hellstrom-Westas L, Groenendaal F, Eken P, de Vries LS 1999 Amplitude integrated EEG 3 and 6 hours after birth in full term neonates with hypoxicischaemic encephalopathy. Arch Dis Child Fetal Neonatal Ed 81:F19-F23

28. Lingwood BE, Dunster KR, Healy GN, Ward LC, Colditz PB 2003 Cerebral impedance and neurological outcome following a mild or severe hypoxic/ischemic episode in neonatal piglets. Brain Res 969:160-167

29. McQueen DS, Bond SM, Smith PJ, Balali-Mood K, Smart D 2004 Cannabidiol lacks the vanilloid VR1-mediated vasorespiratory effects of capsaicin and anandamide in anaesthetised rats. Eur J Pharmacol 491:181-189

30. Durst R, Danenberg H, Gallily R, Mechoulam R, Meir K, Grad E, Beeri R, Pugatsch T, Tarsish E, Lotan C 2007 Cannabidiol, a nonpsychoactive Cannabis constituent, protects against myocardial ischemic reperfusion injury. Am J Physiol Heart Circ Physiol 293:H3602-H3607

31. Tollofsrud PA, Medbo S, Solas AB, Drevon CA, Saugstad OD 2002 Albumin mixed with meconium attenuates pulmonary dysfunction in a newborn piglet model with meconium aspiration. Pediatr Res 52:545-553

32. Sola A, Wen TC, Hamrick SE, Ferriero DM 2005 Potential for protection and repair following injury to the developing brain: a role for erythropoietin? Pediatr Res 2005:110R-117R 